Supporting Information for

\title{
Fast Characterization of Functionalized Silica Materials by Silicon-29 Surface Enhanced NMR Using Dynamic Nuclear Polarization.
}

\begin{abstract}
Moreno Lelli, ${ }^{+}$David Gajan,,,$"$ Anne Lesage, ${ }^{\dagger}$ Marc A. Caporini, ${ }^{\S}$

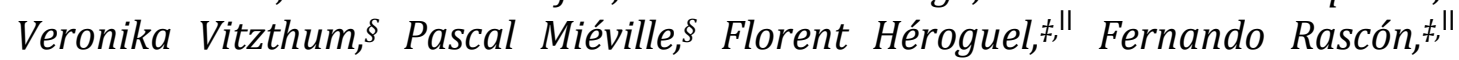
Arthur Roussey, * Chloé Thieuleux, $\neq$ Malika Boualleg, $\neq$ Laurent Veyre, $\neq$ Geoffrey

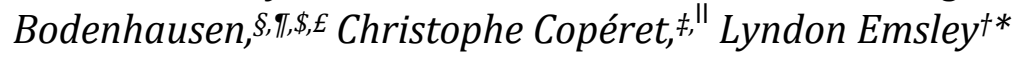

${ }^{\dagger}$ Centre de RMN à Très Hauts Champs, Université de Lyon (CNRS/ENS Lyon/UCB Lyon 1), 69100 Villeurbanne, France; ${ }^{*}$ Université de Lyon, Institut de Chimie de Lyon, C2P2, UMR 5265, (CNRSUniversité Lyon 1-ESCPE Lyon), ESCPE Lyon, 69100, Villeurbanne, France; ${ }^{\S}$ Institut des Sciences et Ingénierie Chimiques, Ecole Polytechnique Fédérale de Lausanne (EPFL), 1015 Lausanne,

Switzerland;: "Department of Chemistry, Wolfgang-Pauli-Str. 10, ETH Zürich, CH-8093 Zürich,

Switzerland; "Département de Chimie, Ecole Normale Supérieure, 75231 Paris Cedex 05, France,

${ }^{\$}$ CNRS, UMR 7203, ${ }^{£}$ Université de Pierre-et-Marie Curie, Place Jussieu, 75005 Paris, France.

*To whom correspondence should be addressed. E-mail: Lyndon.Emsley@ens-lyon.fr

Published XXXX, J. Am. Chem. Soc. XXX, XXX (XXXX)

DOI: XX

\section{This PDF file includes:}

Materials and Methods

Table S1

Figure S1

Figure $\mathrm{S} 2$

References 


\section{Materials and Methods.}

General Information. The reaction of grafting was carried out under inert atmosphere using dried and freshly distilled solvents. All the materials were analyzed after drying under high-vacuum at $135^{\circ} \mathrm{C}$. Tetraethoxysilane (TEOS), pluronic P123, toluene, pentane, acetone, diethylether and ${ }^{2} \mathrm{H}_{2} \mathrm{O}\left(\mathrm{D}_{2} \mathrm{O}\right)$ were purchased from Sigma-Aldrich. Absolute ethanol was purchased from VWR Prolabo. The radical TOTAPOL ${ }^{1}$ and (trimethylsilyl)oxy-4triethoxysilanebenzene ${ }^{2}$ were synthesized following the procedure previously reported in the literature.

DNP-NMR Methods. All DNP-enhanced NMR experiments were performed using a solid-state DNP-NMR spectrometer designed by Bruker-Biospin with specifications given by Rosay et al..$^{3}$ This system consists of a wide-bore $9.4 \mathrm{~T}$ magnet $\left(\omega_{\mathrm{H}} /(2 \pi)=400 \mathrm{MHz}, \omega_{\mathrm{si}} /(2 \pi)=79.4 \mathrm{MHz}\right)$ with a Bruker Avance I spectrometer console, and is equipped with a triple resonance $3.2 \mathrm{~mm}$ lowtemperature CPMAS probe. DNP is achieved by irradiating the sample with highpower microwaves at a frequency of $263 \mathrm{GHz}$. The microwaves are generated by a gyrotron and delivered to the sample by a corrugated wave-guide with $\sim 5 \mathrm{~W}$ of power reaching the sample. The gyrotron operates continuously during the DNPenhanced experiments and has an amplitude stability of better than $\pm 1 \%$. The rotors used are made of sapphire (endowed with $\mathrm{ZrO}_{2}$ caps) for optimal microwave penetration. Spinning frequencies were regulated to $8 \mathrm{kHz} \pm 2$ Hz. The sample temperatures were $\approx 105 \mathrm{~K}$. Chemical shifts are referenced to TMS at $0 \mathrm{ppm}$.

Standard cross-polarization (CP) was used for 1D silicon-29 spectra and 2D ${ }^{1} \mathrm{H}-$ ${ }^{29} \mathrm{Si}$ correlation spectra (the corresponding pulse sequences are shown in Figure S1A). The recycle delay (for DNP) between scans was $1.0 \mathrm{~s}$ in all experiments. The ${ }^{1} \mathrm{H} \pi / 2$ pulse length was $3.1 \mathrm{~ms}\left(v_{1}=80 \mathrm{kHz}\right.$ ). A linear amplitude ramp (from $50 \%$ to $100 \%$ of the nominal RF field strength) was used for the ${ }^{1} \mathrm{H}$ channel, with a $6.0 \mathrm{~ms} \mathrm{CP}$ contact time $\tau_{\mathrm{CP}}$ and a nominal RF field amplitude $\left(v_{1}\right)$ of $71 \mathrm{kHz}$ for ${ }^{1} \mathrm{H}$ and $45 \mathrm{kHz}$ for ${ }^{29} \mathrm{Si}$. SPINAL-64 ${ }^{4}$ proton decoupling was applied during the 
acquisition of the ${ }^{29} \mathrm{Si}$ signal with $v_{1}=82 \mathrm{kHz}$. The 1D fid ${ }^{29} \mathrm{Si}$ acquisition time was $10.0 \mathrm{~ms}$ for 1024 complex points. 1D spectra were processed using exponential window functions with a linebroadening of $75 \mathrm{~Hz}$.

Unless otherwise indicated, similar CP conditions were used for the $2 \mathrm{D}{ }^{1} \mathrm{H}-{ }^{29} \mathrm{Si}$ correlation spectra (Figure 2 and 4 in the main text). The corresponding pulse sequence is shown in Figure S1B. The eDUMBO- $1_{22}$ scheme ${ }^{5}$ was used for ${ }^{1} \mathrm{H}$ homonuclear decoupling during the indirect evolution time with $v_{1}=100 \mathrm{kHz}$ (and a basic eDUMBO cycle of $32 \mu \mathrm{s}$ ). Quadrature detection was achieved using the States-TPPI ${ }^{6}$ scheme by incrementing the phase of the ${ }^{1} \mathrm{H}$ spin-lock pulse of the CP step. A scaling factor of 0.56 was applied to correct the ${ }^{1} \mathrm{H}$ chemical shift scale. $^{5}$ In the spectra of Figure 2 (main text) a total of $64 t_{1}$ increments of $64 \mu \mathrm{s}$ with 8 scans each were recorded, the overall acquisition times in $t_{1}$ and $t_{2}$ were 2.0 and $15.0 \mathrm{~ms}$, respectively; in the spectra of Figure 4 (main text) a total of 48 $t_{1}$ increments of $60 \mu$ s with 112 scans each were recorded, the acquisition times in $t_{1}$ and $t_{2}$ were 1.4 and $15.0 \mathrm{~ms}$, respectively. The 2D spectra were processed with a $4096 \times 2048$ complex points using exponential window functions with linebroadening of $75 \mathrm{~Hz}$ (Figure 2) and $100 \mathrm{~Hz}$ (Figure 4) for the direct dimension and a cosine squared function in the indirect dimension.

Enhancement Factors. Proton DNP enhancement factors $\left(\varepsilon_{H}\right)$ were determined by scaling the intensities of the direct excitation ${ }^{1} \mathrm{H}$ spectra obtained under the same experimental conditions with or without MW irradiation. Silicon-29 DNP enhancement factors $\left(\varepsilon_{\mathrm{Si}}\right)$ were determined by scaling the intensities of the ${ }^{29} \mathrm{Si}$ CP 1D spectra obtained under the same experimental conditions with or without MW irradiation.

Variations in the observed DNP enhancement between different samples could be generated not only by differences in the behavior of the different materials (possible interactions of the radical with the surface, specific interactions of the radical with the organic substrate, ...), but also by the instability in the (today's state of the art) instrumentation. Notably, it is difficult to reproduce exactly the same sample temperature between the samples and over time, and the 
enhancement is very sensitive to temperature in this range (around $\mathrm{T}=100 \mathrm{~K}$ ), with a few degrees colder samples yielding significantly increased enhancements.

NMR Sample Preparation. After wetting the porous materials (I-VI) with the radical solution by incipient wetness impregnation, the $3.2 \mathrm{~mm}$ sapphire rotors were subsequently filled and placed in the NMR probe. Radical solutions were freshly prepared by dissolving TOTAPOL in $\mathrm{D}_{2} \mathrm{O} / \mathrm{H}_{2} \mathrm{O}$ 90:10 to obtain a $9.2 \mathrm{mM}$ TOTAPOL concentration.

Transmission electronic microscopy. Conventional TEM micrographs were performed at the "Centre Technologique des Microstructures", UCBL, Villeurbanne, France, using a Philips 120 CX electron microscope. The acceleration voltage was $120 \mathrm{kV}$. The samples were prepared by dispersing a drop of the ethanol suspension of a ground sample on a $\mathrm{Cu}$ grid covered by a carbon film.

X-Ray Diffraction. Small-Angle X-Ray diffraction (XRD) on powders was carried out with a Bruker D8 Avance diffractometer (33 kV \& $45 \mathrm{~mA}$ ) with $\mathrm{CuK \alpha}$ radiation $(\lambda=0.154 \mathrm{~nm})$ in the "Centre de diffractometrie H. Longchambon", UCBL, Villeurbanne, France. The diffraction patterns were collected in the $2 \theta$ angle range $\left[0.5^{\circ}-10.0^{\circ}\right]$ at a scanning rate of $0.1^{\circ} / \mathrm{min}$. The interplane spacings, $d(h k l)$ for different Miller indices $(h k l)$ were calculated using the Bragg's law $(n \lambda$ $=2 d \sin \theta)$. The lattice parameter $\left(a_{0}\right)$ for the $2 \mathrm{D}$ hexagonal structured mesoporous material is given by $a_{0}=2 d(100) / \sqrt{3}$.

Nitrogen adsorption-desorption measurements. The Nitrogen adsorption and desorption measurements were achieved at $77 \mathrm{~K}$ using an ASAP 2020 Micromeritics system. Before $\mathrm{N}_{2}$ adsorption, the samples were out-gassed at $10^{-4}$ $\mathrm{Pa}$ at $408 \mathrm{~K}$ for $12 \mathrm{~h}$. The pore diameter distribution and the mean pore diameter $\left(d_{p}\right)$ were calculated using the Barrett-Joyner-Halenda $(\mathrm{BJH})$ method. The specific surface area $\left(S_{\mathrm{BET}}\right)$ was calculated with the Brunauer-Emmett-Teller 
(BET) equation. The pore wall thickness $\left(e_{p}\right)$ of the sample was calculated using the following formula: $e_{p}=\sqrt{3 \mathrm{~d}}(100) / 2-d_{p}$.

\section{Preparation of the grafted materials}

Under inert atmosphere, to $0.5 \mathrm{~g}$ of SBA-15 pretreated under high vacuum conditions at $500{ }^{\circ} \mathrm{C}$ for $12 \mathrm{~h}, 330 \mathrm{mg}(1.18 \mathrm{mmol})$ of 1 -(trimethylsilyl)oxy-4triethoxysilanebenzene dissolved in $5 \mathrm{~mL}$ of dry and degassed toluene were added. After $2 \mathrm{~h}$ under reflux conditions, the material was filtered and washed once with $5 \mathrm{~mL}$ of toluene and 3 times with $5 \mathrm{~mL}$ of dry and degassed pentane. The material was then dried under vacuum at room temperature $\left(10^{-5} \mathrm{mbar}\right.$, 4h).

\section{Preparation of the hybrid materials}

\section{Preparation of I. Representative procedure. $^{2}$}

Pluronic $123\left(\mathrm{EO}_{20} \mathrm{PO}_{70} \mathrm{EO}_{20}, 2.95 \mathrm{~g}\right)$ was dissolved in an aqueous $\mathrm{HCl}$ solution (240 mL, pH 1.5) and further poured in a mixture of TEOS (32.6 mmol) and the precursor 1-(trimethylsilyl)oxy-4-triethoxysilanebenzene $(1.2 \mathrm{mmol})$ at room temperature. The reaction mixture was stirred for $2 \mathrm{~h}$ giving rise to a microemulsion (transparent mixture). To the reaction mixture heated at $45^{\circ} \mathrm{C}, \mathrm{NaF}$ (1.2 mmol) was added under stirring. The mixture was left at $45^{\circ} \mathrm{C}$ under stirring for $72 \mathrm{~h}$. The resulting solid was filtered and washed with water, acetone, ethanol and ether. The surfactant was removed by treatment with a mixture of pyridine (30 mL), $\mathrm{H}_{2} \mathrm{O}(30 \mathrm{~mL})$ and $2 \mathrm{M} \mathrm{HCl}(5 \mathrm{~mL})$ at $70{ }^{\circ} \mathrm{C}$ for $12 \mathrm{~h}$. The solid was then filtered, washed with water, acetone and ether and dried at $135{ }^{\circ} \mathrm{C}$ under vacuum $\left(10^{-5}\right.$ mbar, $\left.12 \mathrm{~h}\right)$.

\section{Preparation of II}

The synthesis was carried out following the previously described procedure. ${ }^{7}$

\section{Preparation of III}

The synthesis was carried out following a procedure adapted from the one described above using 1-(trimethylsilyl)oxy-4-triethoxysilane-3,5-diphenyl- 
benzene instead of 1-(trimethylsilyl)oxy-4-triethoxysilanebenzene; molar ratio precursor $/$ TEOS $=1 / 30$.

\section{Preparation of IV}

The synthesis was carried out following the previously described procedure 8 with a molar ratio of chlorobenzyltriethoxysilane/TEOS $=1 / 30$.

\section{Preparation of $\boldsymbol{V}$}

To a homogeneous mixture of P123 (3.84 g, $0.66 \mathrm{mmol}, 0.35$ equiv) dissolved in an aqueous HI solution (pH 1.5, $3.2 \mathrm{~g}$ ), TEOS (7.30 g, $35.04 \mathrm{mmol}, 19.0$ eq.) was added. The mixture was vigorously stirred until a transparent solution was obtained, and the silylated molecular precursor $\mathrm{N}, \mathrm{N}$-bis(3propyltriethoxysilyl)imidazolium iodide (1.12 g, $1.84 \mathrm{mmol}, 1.0 \mathrm{eq}$.) was then added. The reaction mixture was further stirred for $30 \mathrm{~min}$, and the ethanol was evacuated under vacuum to yield a pale yellow gel. After $24 \mathrm{~h}$ at $25^{\circ} \mathrm{C}$, water $(0.8$ $\mathrm{mL}$ ) was added and the reaction mixture was heated at $100^{\circ} \mathrm{C}$ for $24 \mathrm{~h}$. The resulting gel was finally grinded into a powder, which was then washed successively with water, ethanol, acetone and diethyl ether. The surfactant was removed by soxhlet extraction in hot ethanol for 3 days. The material was washed with water, ethanol, acetone, diethyl ether, and then dried by heating at $135^{\circ} \mathrm{C}$ under high vacuum $\left(10^{-5} \mathrm{mbar}\right)$ for $12 \mathrm{~h}$ to yield the material obtained as a slightly yellowish powder (2.6 g, Yield = 93\%). ${ }^{13} \mathrm{C}$ NMR (75.5 MHz, CPMAS, $\left.25^{\circ} \mathrm{C}\right) \delta 8.0\left(\mathrm{CH}_{2}-\mathrm{Si}\right), 23.1\left(\mathrm{CH}_{2}\right), 51.2\left(\mathrm{CH}_{2}-\mathrm{N}\right), 122.2(\mathrm{CH}=\mathrm{CH}), 136.1(\mathrm{~N}-\mathrm{C}=\mathrm{N})$; ${ }^{29} \mathrm{Si} \mathrm{NMR}\left(59.6 \mathrm{MHz}, \mathrm{CP} \mathrm{MAS}, 25^{\circ} \mathrm{C}\right) \delta-59\left(\mathrm{~T}^{2}\right),-67\left(\mathrm{~T}^{3}\right),-91\left(\mathrm{Q}^{2}\right),-101\left(\mathrm{Q}^{3}\right),-110$ $\left(Q^{4}\right)$.

\section{Preparation of $\mathbf{V I}$}

The synthesis was carried out following the previously described procedure ${ }^{9}$ with a molar ratio of precursor to TEOS $=1 / 19$.

Table S1. Physical characteristics of the materials I-VI.

$\begin{array}{cccccc}\text { Materials } & \begin{array}{c}\text { Surface Area } \\ \left(\mathrm{m}^{2} / \mathrm{g}\right)^{\mathrm{a}}\end{array} & \begin{array}{c}\text { Pore } \\ \text { volume } \\ \left(\mathrm{cm}^{3} / \mathrm{g}\right)^{\mathrm{b}}\end{array} & \begin{array}{c}\text { Average } \\ \text { pore } \\ \text { diameter } \\ \mathrm{d}_{\mathrm{p}}(\mathrm{nm})^{\mathrm{b}}\end{array} & \begin{array}{c}\text { Lattice } \\ \text { parameter } \\ a_{0}(\mathrm{~nm})^{\mathrm{d}}\end{array} & \begin{array}{c}\text { TEM } \\ \text { and XRD }\end{array} \\ \end{array}$




\begin{tabular}{cccccc}
\hline I & 925 & 0.96 & 8.00 & 10.6 & 2D hexagonal \\
II & 619 & 0.85 & 5.56 & 12.6 & 2D hexagonal \\
III & 993 & 1.35 & 5.43 & - & Worm-like \\
IV & 361 & 0.60 & 10.4 & 12.0 & 2D hexagonal \\
V & 567 & 0.6 & 6.6 & 10.2 & 2D hexagonal \\
VI & 619 & 0.82 & 10.1 & 11.7 & 2D hexagonal \\
\hline
\end{tabular}

${ }^{a}$ Calculated with the BET method; ${ }^{b}$ Calculated with the BJH method on the adsorption branch of the isotherm; ${ }^{c}$ Calculated with the t-plot method; ${ }^{d}$ Calculated from the XRD pattern $\mathrm{a}_{0}=(2 \mathrm{~d} 100) / \sqrt{3}$. 
A

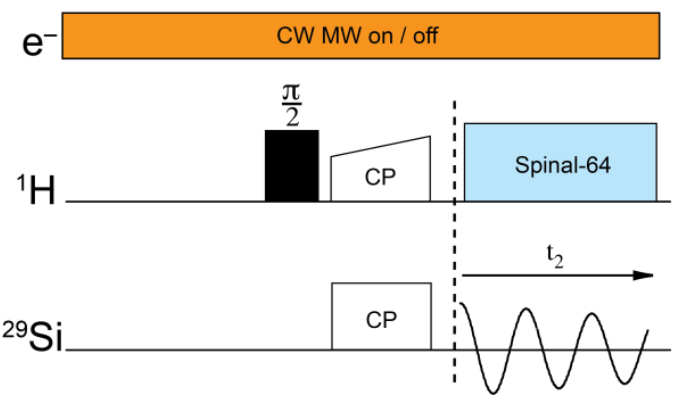

B

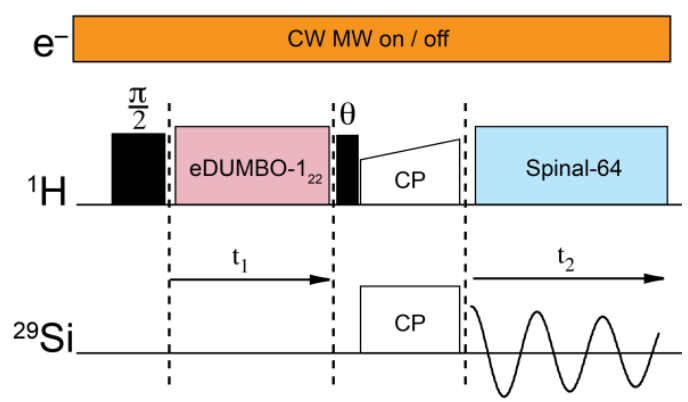

Figure S1. (A) $1 \mathrm{D}{ }^{29} \mathrm{Si}$ cross-polarization pulse sequence used to obtain the NMR spectra. (B) 2D pulse sequence for the ${ }^{1} \mathrm{H}-29 \mathrm{Si}$ heteronuclear correlation spectra. Pulse sequences and phase cycles are available upon request.

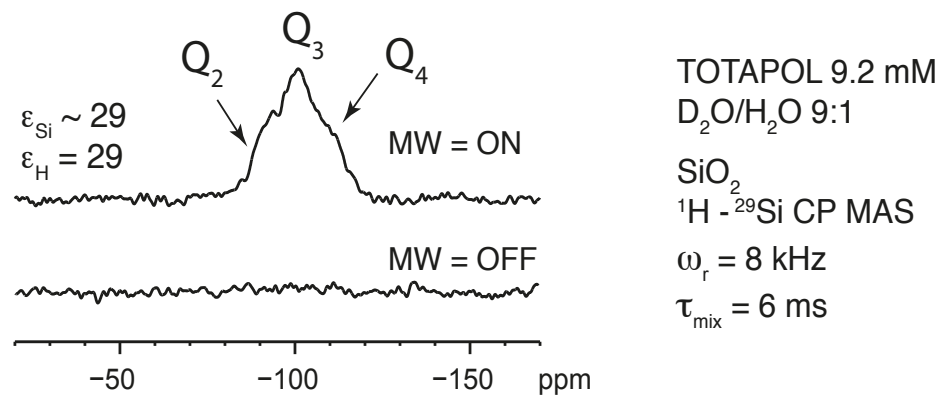

Figure S2. 1D ${ }^{29} \mathrm{Si}$ cross-polarization spectra of the pure flame silica powder (not functionalized) with (upper) and without (lower) MW irradiation at $263 \mathrm{GHz}$ to induce DNP. Both spectra were recorded with 2048 scans, with an interval between scans of $1 \mathrm{~s}$ (total acquisition time $\sim 35 \mathrm{~min}$ ). The cross polarization contact time $\tau_{\mathrm{CP}}$ was $6 \mathrm{~ms}$. Notably, the low intensity of the $\mathrm{Q}_{4}$ species indicates we observe preferentially the surface, solvent-exposed, $\mathrm{Q}_{4}$ atoms, and the body of the material is not observed. The lower intensity of the signal in the DNP enhanced spectra compared with the spectra obtained under the same conditions for the hybrid materials is accounted for by the lower surface area of the silica powder $\left(\sim 200 \mathrm{~m}_{2} / \mathrm{g}\right.$ for $\left.\mathrm{SiO}_{2}\right)$. 


\section{References}

(1) Song, C. S.; Hu, K. N.; Joo, C. G.; Swager, T. M.; Griffin, R. G., J. Am. Chem. Soc. 2006, 128, 11385-11390.

(2) Lesage, A.; Lelli, M.; Gajan, D.; Caporini, M. A.; Vitzthum, V.; Miéville, P.; Alauzun, J.; Roussey, A.; Thieuleux, C.; Medhi, A.; Bodenhausen, G.; Copéret, C.; Emsley, L., J. Am. Chem. Soc. 2010, 132, 15459-15461.

(3) Rosay, M.; Tometich, L.; Pawsey, S.; Bader, R.; Schauwecker, R.; Blank, M.; Borchard, P. M.; Cauffman, S. R.; Felch, K. L.; Weber, R. T.; Temkin, R. J.; Griffin, R. G.; Maas, W. E., Phys. Chem. Chem. Phys. 2010, 12, 5850-5860.

(4) Fung, B. M.; Khitrin, A. K.; Ermolaev, K., J. Magn. Res. 2000, 142, 97-101.

(5) Elena, B.; de Paepe, G.; Emsley, L., Chem. Phys. Lett. 2004, 398, 532-538.

(6) Marion, D.; Ikura, M.; Tschudin, R.; Bax, A., J. Magn. Res. 1989, 85, 393-399.

(7) Rascón, F.; Berthoud, R.; Wischert, R.; Lukens, W.; Copéret, C., J. Phys. Chem. $C$ online.

(8) Maishal, T. K.; Alauzun, J.; Basset, J. M.; Coperet, C.; Corriu, R. J. P.; Jeanneau, E.; Mehdi, A.; Reye, C.; Veyre, L.; Thieuleux, C., Angew. Chem. Int. Ed. 2008, 47, 8654-8656.

(9) Alauzun, J.; Mehdi, A.; Reye, C.; Corriu, R., New J. Chem. 2007, 31, 911-915. 